\title{
DESLINDE DE VIVENCIAS EN LA HISTORIA MEXICANA
}

Natural es que en un centro de formación de historiadores se invite, a quienes desde hace años practican el oficio, a comunicar sus experiencias y reflexiones acerca del mismo. En los últimos tiempos he tenido la oportunidad de hacerlo en dos ocasiones. En primer lugar, cuando el historiador inglés radicado ahora en los Estados Unidos de América, Peter Bakewell, quiso recoger mi opinión con motivo de una encuesta abierta por la Hispanic American Historical Review en 1982, texto que ampliado reedité en la Memoria de El Colegio Nacional de México al fin del mismo año. Refiriéndome a los historiadores de los Estados Unidos de América de fines del siglo xIx y comienzos del xx, recordaba que habían recibido la influencia de los seminarios alemanes y contaban con profesores como Bolton, Haring, Robertson y otros que formaron a historiadores más jóvenes de mucha capacidad de trabajo y de comprensión del pasado. Ellos, como ocurrió en los casos notables de Aiton y de Scholes, tuvieron el apoyo documental muy valioso del Archivo General de Indias; de suerte que cuando leíamos sus trabajos en los países de habla española de América, nos comunicaban fuentes que no estaban fácilmente a nuestro alcance. Por lo que ve a la historiografía posterior que se ha desarrollado en la segunda mitad del siglo $\mathrm{xx}$, es cierto que proporciona elementos que ensanchan el conocimiento de nuestros temas; pero observo en ella ciertas desviaciones. La anterior era modesta y trataba de apoyar sus verdades en la documentación consultada. Una parte de la actual sabe y dicta todo. Le regala al pasado sus modelos, sus ideas, su lenguaje gremial. Con el tiempo puede ocurrir que indicará más sobre el siglo xx que sobre los siglos anteriores que pretende estudiar. A mí, tal vez por la edad, aunque creo que asimismo por el razonamiento, me gusta más la posición anterior. 
En la referida entrevista hice notar que primero se había estudiado la historia política de los Estados, de los hombres de gobierno, de las leyes, etcétera. Mas ese enfoque empezó a cambiar en el curso del siglo xIx y, principalmente en Europa, vino el movimiento que se llamaba de historia de la civilización. Yo tuve un maestro español distinguido que propició ese cambio, don Rafael Altamira, autor quizá de la primera historia de la civilización española entendida de la nueva manera. Después de tal mirada más amplia a la historia, que no sólo incluía el fenómeno político sino las ideas, la vida social, las letras y las artes, ha venido una fuerte corriente de índole económica que ha llevado con el tiempo a la historia cuantitativa - de curvas de precios, de producción y circulación de metales, de cifras de población aunque sean inventadas, de embarques, etcétera- considerada casi como única, lo cual no es cierto. Después se ha querido - y es particularmente en los Estados Unidos de América donde observo semejante movimiento como consecuencia de la recepción de las enseñanzas de la escuela francesa de los Anales- reducir el enfoque a buscar al hombre pequeño, al que dejó una huella pasajera en algún olvidado archivo notarial, para sostener que ésa es la verdadera historia. Si nos detenemos a ver cómo y por qué ha pasado esto, nos daremos cuenta del camino que se ha recorrido por etapas, aunque no tenemos necesidad de aceptar las conclusiones; dado que, si bien se amplía la visión a capas de la población que antes solían ser olvidadas, y esto es positivo, de otra parte, se pretende desconocer la utilidad de alzarse a comprender las ideas influyentes de una época, el papel de los hombres con posibilidad de tomar decisiones importantes en ella, cuál era el funcionamiento de las instituciones, en suma, la complejidad de la realidad histórica que afecta a esos mismos estratos modestos que se rescatan como objeto preferente o casi exclusivo del examen retrospectivo. Por ello he advertido en congreso reciente que una ignorancia deliberada de aquellos elementos determinantes de la historia no debe presentarse como una virtud metodológica. Y agrego que todavía hace unos años, en plena hecatombe de la Segunda Guerra Mundial, había colegas nuestros que repetían y enseñaban que el error de la historiografía tradicional, la que llamaban "evenemencial" ' o de los acontecimientos, había sido fijarse en los Estados y en las guerras. Y lo decían precisamente en aquella coyuntura en la que todos teníamos que estar pendientes de quién iba a ganar en la contienda, lo cual era de suma importancia para el mundo que continuaría viviendo, incluyendo a sus capas más 
modestas y sacrificadas. Por eso, sin desconocer las razones y los aciertos de inclusión de ciertos modos de ver actuales (yo mismo he estudiado a gentes humildes como los esclavos indios y los indios repartidos para los servicios personales en la Nueva España, aunque sin dejar por ello de considerar las ideas, las disposiciones legales y los actos de las autoridades altas o menores que intervenían en los procesos), estoy lejos de pensar que esas tendencias hacia el estudio de la historia de clases menores vayan a quedar en su conjunto como una verdad única y duradera. Incluso ya se da el caso de investigadores de series numéricas que, cansados de ellas, se acogen a la historia de las mentalidades antes llamada de las ideas. A mi ver la pluralidad en los enfoques de la historiografía es conveniente para el mejor y más completo conocimiento y comprensión de la historia. No creo que una sola clave abra sus puertas para llegar a la verdad, y desconfío de las modas que sabemos son pasajeras.

Dadas las fechas de mi nacimiento y de la entrevista referida, no dejé de puntualizar que a medida que la vida avanza se gana conciencia de que, por mucho que el historiador se aplique y rinda en su tarea, siempre el dominio del pasado le seguirá pareciendo inagotable, y por ello considerará como modestos e insuficientes los conocimientos que alcanza y lega a quienes vienen después a continuar la labor a lo largo de la marcha del tiempo. Se puede reconocer el estudio de la historia como una de las ocupaciones propias del homo sapiens; pero quien rema en frágil barca en el océano del conocimiento histórico aprende que el horizonte es infinito; el avance, si alguno hay, es limitado y sólo realizable a corta distancia; mas por ello mismo sabe que esa labor no puede agotarse y que dará razón a su empeño hasta en los últimos años de su existencia.

Ahora bien, ¿por qué o para qué como ahora se pregunta toda esta labor, la propia y la de los discípulos que se logren formar y rindan sus frutos a su manera? Solamente a causa de que sabemos que la generación viviente no abarca a toda la humanidad; que ésta existe desde tiempos remotos (los etnólogos, los historiadores y aun los hombres comunes sentimos la atracción por el análisis de la vida de nuestros ancestros primitivos y por lo que nos enseñan acerca de la especie a la que pertenecemos); y que probablemente el género humano, dejando a salvo los designios de la Providencia que no conocemos, seguirá existiendo en el futuro si la tierra y nuestros errores lo permiten. Entonces, tenemos conciencia de que si por medio del estudio histórico (en su caso el 
arqueológico y el etnológico, además de otras ciencias que solemos llamar auxiliares pero que tienen su propia entidad como la geografía humana), podemos extender la vista del presente inmediato a otras experiencias y saberes de la especie humana, cabe y debemos aplicarnos a dicho empeño, al menos en la pequeña fracción de humanidad que somos los historiadores. No todos los hombres van a dedicarse al estudio de la historia; hagámoslo por ellos a fin de transmitirles los fragmentos de conocimiento del pasado que alcancemos, los rasgos de sensibilidad que percibamos en las generaciones anteriores, las huellas de vida y de creación que ellas han dejado a través de los testimonios; en suma, ensayemos la comprensión del género humano y de las sociedades en la medida que la historia nos ayuda a tenerla.

Decía al principio de estas líneas que hubo una segunda ocasión reciente en la que tuve la oportunidad de comunicar mis reflexiones acerca del arte que los historiadores practicamos; pero fue en relación con la época española de la historia de México y no en el ámbito más general del que antes hemos tratado.

Existe en los alrededores de París un Liceo Internacional en Saint Germain-en-Laye, que aplica bien las reglas propias del bachillerato francés a jóvenes en edad de recibirlo, y tiene la particularidad de contar con Secciones adicionales que ofrecen conocimientos sobre idiomas y culturas de otras partes como son la alemana, la inglesa y la española que en los últimos tiempos ha procurado abarcar asimismo conocimientos sobre Hispanoamérica. Por esta razón se organizó un ciclo de conferencias relativas a México y fui invitado a dar la plática final en el año de 1986.

Recordé en tal ocasión que tenemos el hábito de distinguir tres grandes etapas de la historia mexicana: una, que solemos llamar prehispánica, que se extiende por lo menos a doce mil años antes de nuestra era con unos seis mil ya de agricultura. Es sabido que esa etapa produjo grandes culturas, no perfectas como nada de lo humano lo es, pero podemos reconocer que han dejado una raigambre indígena todavía perceptible por medio de la contemplación de las ruinas, el estudio de ellas y de los testimonios, el contacto con los grupos subsistentes de población diversos como son el maya, el mixteca y zapoteca, el purépecha, el totonaca, el mexica del centro entre otros.

La segunda etapa, que suele designarse como colonial, dura tres siglos, desde la conquista en 1519-1521 hasta la guerra de independencia que se desarrolla de 1810 a 1821 . Su legado tampoco ha desaparecido: como suele pasar en los países que tienen his- 
toria -y México es uno de ellos-, sucesivos legados del tiempo se van acumulando y siguen presentes hasta la actualidad.

Consumada la ruptura política y la separación de España al cabo de esos once años de lucha, da comienzo la tercera etapa de la vida independiente o nacional, en la cual se distinguen dos movimientos de gran significación: uno, el llamado de la Reforma, con la figura de Benito Juárez y la Constitución liberal de 1857; y otro, el de la Revolución iniciada en 1910, que deja la Constitución de 1917 todavía vigente con muchas enmiendas.

En lo que respecta a la segunda etapa, notemos que comienza por trágicos episodios de conquista y termina con otra larga guerra de independencia que puso término a la dominación política hispana. Se comprende por ello que, si bien nadie puede dudar sensatamente de que el contacto de gentes indígenas, europeas, africanas, asiáticas, con sus mezclas, así como los enlaces de culturas, estaban creando un nuevo pueblo y otro marco de civilización, no iba a ser fácil que los sentimientos de los habitantes de la Nueva España y luego del México independiente, pudieran asimilar fácilmente las complejidades de esa historia.

Cuando llega la crisis de la independencia, algunas plumas la presentan como una reconquista de la soberanía indígena perdida a raíz de la llegada de los españoles. Otras la interpretan como una reclamación de los derechos de los descendientes criollos de los conquistadores y primeros pobladores que - argumentaban- los monarcas españoles no habían respetado. Los peninsulares ocuparon los puestos principales, no trataron a la gente nacida en el país con las consideraciones a las que tenía derecho de acuerdo con el pacto inicial de la emigración concertado con la monarquía. De ahí la reclamación de los criollos americanos (acompañada por la de los demás componentes de la población que asimismo hacían valer sus agravios) llamada a cobrar fuerza a principios del siglo XIX con motivo de la abdicación de los reyes por efecto de la invasión napoleónica de la Península. Sigue la guerra de insurgencia y por fin la separación política de España con la proclamación de la independencia. Como el enemigo a vencer era la autoridad española, todo ello venía acompañado de fuertes denuncias contra la etapa que estaba por terminar, no sin contradicciones evidentes, como la de enarbolar los insurgentes el estandarte de la Virgen de Guadalupe, escribir las proclamas y las nuevas leyes en buen español, dividir a las familias entre sí, reclamar los territorios extensos que se habían ganado en los siglos de la colonización y que llegaban hasta Nuevo México de una par- 
te, hasta la Alta California de la otra, aspirar a ejercer el derecho de patronato del Estado sobre la Iglesia según lo habían ejercido los reyes de España, basar la propiedad del suelo en las ciudades o en los campos en los viejos títulos de las mercedes españolas, usufructuar el patrimonio artístico creado por los estilos de la etapa anterior en particular en los templos, seguir practicando usos y costumbres bien enraizados como los de las corridas de toros y los de la charrería mexicana (con el sarape de lana sobre los hombros, la música de la guitarra, la danza con el taconeo traída por la gente venida de España). Tampoco se podía prescindir de la cultura material que llegó con la colonización europea: nuevas plantas, como el trigo; animales útiles de vianda, tiro y carga; las técnicas de la explotación minera; la navegación de la canoa complementada o sustituida por los bergantines y las naos del océano; el uso de la pólvora y de las armas que trajeron los conquistadores.

Durante la guerra de la independencia aparece otra división ideológica y política que afecta tanto a la metrópoli española como a las posesiones que se separan de ella. Me refiero a la que surge entre los conservadores y los liberales. Un liberal navarro, Francisco Javier Mina, toma partido por los insurgentes de México, porque su enemigo es el rey absoluto de España, Fernando VII, y él lo combate como tal lo mismo en Navarra que en México. En la incipiente vida nacional estos dos partidos siguen oponiéndose y su concepción de la historia es distinta. Un historiador y político conservador como Lucas Alamán trató de apoyarse en el pasado español de los tres siglos que concluían al nacer el México independiente, con la esperanza de asegurar el orden civil y la defensa de la amenazada frontera del norte, que acabó por perderse en la guerra con los angloamericanos en 1847. La historiografía liberal, influida por la Ilustración y la Leyenda negra antiespañola, consideraba que todos los males tenían su origen en ese pasado español al que se ponía término: el despotismo político, la religión intolerante con su inquisición, la formación de los latifundios, la explotación social de los indígenas y de los africanos esclavizados. Los países nuevos que se independizaban en América sólo podían progresar alejándose de ese pasado inconveniente. Sin embargo, algunos destacados pensadores del partido liberal, como Vicente Riva Palacio y Justo Sierra, moderaron esa concepción porque advertían que en los tres siglos de la colonización se formó un nuevo país que venía de la doble raíz indígena e hispana, con añadidura de los hombres y los elemen- 
tos de cultura procedentes de África y de Asia. La independencia no debía verse como si la vieja nación conquistada recobrara su libertad después de trescientos años de dominación extranjera; porque el pueblo mexicano se había formado durante esos tres siglos del gobierno español con el trabajo de la crisálida y heterogéneos componentes. Así se creó la individualidad social y política que proclamó su emancipación en 1810. Sierra, como Secretario de Instrucción Pública, pensaba en la necesidad de unificar el habla nacional castellana en una nación que era vecina de un gigantesco conglomerado de lengua inglesa radicalmente distinta.

En cuanto a la terminología, es de notar que predomina el hábito de llamar a esa segunda época, colonial o de la colonización española en México. A fines del siglo xix se hablaba mucho también de la dominación española en México. Pero uno de los ideólogos de la independencia, fray Servando Teresa de Mier, esgrimía entre sus argumentos que las posesiones españolas de América no eran colonias sino reinos, los cuales al desaparecer la unión con el soberano por efecto de la invasión napoleónica de la Península, recobraban su autonomía como lo habían hecho las regiones españolas creando sus Juntas de defensa. Ahora bien, esta interpretación llevaba en el caso de América a consagrar la independencia de tales posesiones, como la reclamaban sus cabildos y luego los movimientos insurgentes. Fuera de reparos semejantes, a mí no me incomoda el uso del término "colonial", que se ha difundido sobre todo en el campo del arte; pero he reflexionado en los últimos tiempos, como antes lo hizo el historiador argentino Ricardo Levene, que así como decimos la época prehispánica de la historia de México sin ningún embarazo, podríamos hablar de la época española o hispánica para designar a la etapa intermedia entre ese pasado indígena y la época nacional que sigue a la independencia. Finalmente me he inclinado más bien por la denominación de la época hispánica, porque si en varias de las actividades venía la dirección de España, no abarcaba la vida entera del país en los tres siglos que van del xvi al xix. En las manifestaciones principales, como la construcción de la catedral de México, los trabajos del desagüe del Valle central, la navegación a Filipinas, las expediciones que llegaron hasta Alaska, las creaciones de las ciudades y del arte, se hacía presente una labor constante de la gente del país (incluyendo europeos distintos de los españoles, judíos, moriscos; criollos, mestizos, indios; negros, mulatos; chinos o filipinos; y las castas provenientes de los cruces étnicos). El empleo de la denominación de época hispánica permite 
incluir a esos varios elementos sin limitarlos a los peninsulares, mejor que si se hablara de la época española que pudiera entenderse como obra única de éstos.

$\mathrm{Y}$ antes de terminar estas consideraciones relativas a la conquista y a la colonización trisecular hispano-mexicana, quisiera hacer notar que desde hace bastantes años estimo que debiéramos tanto los españoles como los hispanoamericanos prestar mayor atención al paralelo que existe entre tales hechos ocurridos en el Nuevo Mundo y los anteriores de la conquista y la colonización de Roma en la Península Ibérica, que dura a su vez alrededor de seis siglos. Porque una y otra etapa comienzan por guerras de conquista, y así como en México se recuerda a los defensores indígenas de Tenochtitlan y sobre todo a Cuauhtémoc frente a Hernán Cortés, en España se cuenta con la resistencia que oponen los defensores iberos de Numancia a las aguerridas legiones de Roma hasta el último sacrificio, el cual fue inmortalizado en el drama de Cervantes, y se encuentra bien recordado actualmente en el Museo Arqueológico de Madrid. Luego se fundan en la Península Ibérica las grandes ciudades como Mérida y se construyen las calzadas y demás obras romanas, como España a su vez lleva al Nuevo Mundo el urbanismo en damero que puede verse todavía en Mérida de Yucatán, las fortalezas, los puentes y los acueductos. En el campo del derecho, claro es que en la Península Ibérica penetra el genio romano como a su vez los teólogos y los juristas españoles llevan el suyo al Nuevo Mundo. En un caso el latín incuba la lengua romance que perdura en el español actual. En el otro, llega el castellano, se extiende por los vastos confines del hemisferio nuevo, y se mantiene en el idioma español hispanoamericano de nuestros días, a pesar de las distancias, de los cambios naturales de ambiente, y de los inevitables contactos con otras hablas indígenas. Por eso en mis años de estudiante en España oía que algunos profesores, como don Fernando de los Ríos, enseñaban que tocó a España, después del descubrimiento colombino, convertirse en la Roma del siglo xvi. Pienso que a los historiadores y a los estudiantes de Roma, de España y de América, nos convendría ahondar en estas comparaciones que nos habituarían a mirar mejor las particularidades de nuestras respectivas historias. Por ello he visto con interés la publicación de la obra de Jaime González, La idea de Roma en la Historiografía Indiana (1492$1550)^{1}$, que se propone examinar la presencia de la idea de Ro-

${ }^{1}$ Instituto Gonzalo Fernández de Oviedo, Madrid, 1981. 
ma en algunos historiadores de la época de Carlos $\mathrm{V}$ relacionados de una manera u otra con América. Considera que en pleno Renacimiento, España está repitiendo la hazaña de Roma, y la referencia al Imperio Romano era inevitable. Ahora bien, el propio autor aclara que la referencia a la idea de Roma no significa establecer la semejanza sustancial de fines y de métodos entre el Imperio español y el romano. Tal tesis exigiría un estudio mucho más amplio y de caracteres diferentes al de este autor. Sólo aspira a hacer un análisis de mentalidad sobre uno de los componentes más claros de la primera mitad del siglo xvi, teniendo presente la distancia entre la Antigüedad y el Cristianismo. Sólo Ginés de Sepúlveda intentó una síntesis de la moral pagana con la cristiana sabiendo a lo que se exponía. Bartolomé de las Casas fue el autor radical (en la condenación de las conquistas romanas) de los que va a estudiar. Como se ve, el campo sigue abierto.

Y ya que el curso de estas palabras nos ha llevado a acercarnos a la llegada de Cristóbal Colón al Nuevo Mundo en 1492, detengámonos, así sea brevemente, a observar lo que ha sucedido en México con respecto a la conmemoración del V Centenario de ese acontecimiento de tanta significación para la historia universal.

Con la aparente sencillez de un cambio terminológico, se propuso que, en vez de seguir hablando del descubrimiento como se había venido haciendo desde 1492 "por hábito euro-centrista", se pasara a hablar de un encuentro de dos culturas o dos mundos; luego se ha abandonado la idea inicial de las dos culturas ante las dificultades evidentes de considerar como una sola a la española tan compleja al salir de la Edad Media por la coexistencia de cristianos, musulmanes y judíos; y como otra a la multiplicidad de grupos de naturales hallados en el Nuevo Mundo y en particular en el suelo mexicano, a los que ya nos hemos referido. Aun reducido el caso a dos mundos, el antiguo y el nuevo, se presentaba el obstáculo de dejar de lado a los africanos y a los asiáticos que fueron traídos en los barcos europeos, suponiendo forzadamente que las tres partes antiguas de la tierra: Europa, África y Asia, formaban un solo viejo mundo o antiguo, frente al nuevo hallado en América que se presentaba a su vez como si fuera uno solo. Claro es que el propósito conceptual era el de relegar al olvido o restar importancia a los descubrimientos y a los establecimientos de los europeos en el Nuevo Mundo, para hacer resaltar la presencia de los habitantes indígenas que se encontraban anteriormente en esas tierras. 
$\mathrm{Ni}$ esa aventura del pensamiento histórico ni el cambio terminológico propuesto recibieron la aprobación unánime de los estudiosos de la época. No poco se ha escrito y polemizado en torno de tal episodio.

Los reparos que por mi parte he puesto a esa pretensión pueden verse en mi "Examen del título de la conmemoración...", de 1986 , y en mi "Excursión por el Diccionario de la Academia de la Lengua con motivo del V Centenario...'”, de $1987^{3}$, estudios que no viene al caso resumir aquí. Digamos solamente que me ha parecido que interpretó mejor lo ocurrido en la era de las grandes navegaciones el historiador mexicano de larga residencia en España Carlos Pereyra cuando habló de la conquista de las rutas oceánicas, a la cual siguieron los encuentros múltiples en las varias partes de la tierra descubierta con gentes, religiones, culturas, lenguas y productos distintos. Esto a su vez llevó al filósofo mexicano José Vasconcelos a formular su teoría de la raza cósmica en el Nuevo Mundo, como resultado del acercamiento de las cuatro que venían existiendo separadamente: la indígena, la europea, la africana y la asiática. Tales planteamientos me parecen más acertados histórica y lingüísticamente que los de la aventura del "encuentro de dos mundos" que no permiten cubrir cabalmente la era histórica de la que se trata, ni mejoran el lenguaje que desde fines del siglo xv se ha venido empleando apropiadamente para tratar de los viajes colombinos y de los otros navegantes oceánicos, así como de sus consecuencias que cambiaron la faz del mundo hasta entonces conocido.

Al acercarse el año de 1992, podrá recordarse que partió de México la apresurada propuesta del cambio de la terminología tradicional del descubrimiento por la del encuentro de dos culturas o dos mundos; pero cabrá decir asimismo que la historiografía mexicana no ha dejado de criticarla y de poner en evidencia que la razón histórica, la recta intención del estudio y el lenguaje apropiado empleado desde la época de los acontecimientos que se conmemoran, desautorizan esa innovación de tendencia cuestionable.

${ }^{2} \mathrm{El}$ "Examen del título de la conmemoración del $\mathrm{V}$ centenario del descubrimiento de América" apareció inicialmente en Mar Abierto, México, 1985, núm. 3, 16-20. También se encuentra en mi obra Temas hispanoamericanos en su quinto centenario, Porrúa, México, 1986, pp. 15-29.

3 "Excursión por el Diccionario de la Academia de la Lengua, con motivo del V Centenario del Descubrimiento de América", NRFH, 35 (1987), 265-280. 
Al poner término a estas líneas, hagamos notar que no he tratado a lo largo de ellas de abordar la historia solamente desde el punto de vista de la reflexión metodológica, sino que he intentado seguir el curso de las vivencias de las sociedades de la Nueva España y luego del México independiente al correr del tiempo desde la conquista de 1519-1521 hasta nuestros días. Con el complemento de las lecturas recomendables, espero que este resumen podrá resultar de algún provecho para los lectores de su texto.

Silvio Zavala El Colegio de México Profesor Emérito 